\title{
Prognostic significance of insulin-like growth factor-II mRNA-binding protein 3 in urological cancers: a systemic review and meta-analysis
}

\author{
Da-wei Sun ${ }^{1}$, Ying-yi Zhang ${ }^{2}$, Yue Qi ${ }^{3}$, Yu-guo Chen ${ }^{1}$, Jian Ma ${ }^{1}$, Gui-qi Liu' ${ }^{1}$ and Guo-yue Lv $^{1 *}$ \\ ${ }^{1}$ Department of Hepatobiliary and Pancreatic Surgery, The First Bethune Hospital, Jilin University, Jilin 130021, China \\ ${ }^{2}$ Department of Oncology, Peking Union Medical College Hospital, Chinese Academy of Medical Sciences and Peking Union Medical College, Beijing 100730, \\ China \\ ${ }^{3}$ Department of Hepatobiliary and Pancreatic Medicine, The First Bethune Hospital, Jilin University, Jilin 130021, China
}

\begin{abstract}
Purpose: Insulin-like growth factor II mRNA-binding protein 3 (IMP3) is an oncofetal protein expressed in diverse malignancies. This study aimed to investigate the prognostic value of IMP3 in urological cancers.

Methods: Eligible studies were sought in PubMed, Embase, Cochrane Collaboration and Wanfang databases. Pooled hazard ratios (HRs) with their 95\% confidence intervals (CIs) were used to assess the prognostic value of IMP3 in patients with urological cancers.

Results: Eight studies including 2,219 patients were enrolled in this meta-analysis. The pooled results showed that IMP3 expression was an indicator of poorer prognosis in patients with urological cancers in terms of overall survival (OS) (HR 2.19, 95\% CI 1.35-3.55), disease-specific survival (DSS) (HR 2.10, 95\% CI 1.53-2.89), disease-free survival (DFS) (HR 1.49, 95\% CI 1.18-1.87) and metastasis-free survival (MFS) (HR 3.80, 95\% CI 2.27-6.34). Subgroup analyses revealed that IMP3 was significantly correlated with poorer prognosis in patients with kidney cancer or urothelial cancer in terms of OS (HR 2.52; 95\% CI 1.55-4.10), DSS (HR 2.11; 95\% CI 1.51-2.95), DFS (HR 2.01; 95\% CI 1.40-2.88) and MFS (HR 3.80; 95\% CI 2.27-6.34), whereas this association was not found in patients with prostate cancer (OS, HR 1.09, 95\% CI 0.45-2.63; DSS, HR 2.06, 95\% CI 0.73-5.80; DFS, HR 1.20, 95\% CI 0.88-1.62).
\end{abstract}

Conclusions: IMP3 expression might be an indicator of poor prognosis in patients with kidney cancer or urothelial cancer. Further large prospective and welldesigned studies utilizing better IMP3 expression assessment processes, are needed to confirm these results especially in patients with prostate cancer.

\section{Introduction}

Cancer is a major public health problem around the world. It is currently the second leading cause of death in the United States, and is expected to surpass heart diseases as the leading cause of death in the next few years [1]. Urological cancers mainly including kidney cancer, urothelial cancer and prostate cancer are common types of malignancies worldwide especially in western countries. According to the GLOBOCAN 2008 estimates, about 386,300 new cases and 150,200 deaths from bladder cancer, and 903,500 new cases and 258,400 deaths from prostate cancer occurred in 2008 worldwide [2]. With the advent of screening molecular marker prostate-specific antigen (PSA) and the advances of treatment modalities such as endocrine therapy and molecular targeted therapy, the 5-year survival rate in patients with prostate cancer has improved, which is more than 99\% [1]. However, the prognosis of patients with kidney cancers and bladder cancers remains unpleasant, for which 5-year survival is 74\% and $79 \%$, respectively [1]. Therefore, it is essential to identify biological markers for diagnosing urological cancers in their early stages and predicting the prognosis such as recurrence and metastasis after treatments.

IMP3 is a member of insulin-like growth factor-II m-RNA-binding protein (IMP) family that consists of IMP1, IMP2 and IMP3 [3]. IMPs are especially expressed in developing epithelium, muscle, and placenta in both human and mouse embryos [3], and play an important role in RNA trafficking and stabilization, cell growth, and cell migration during the early stages of embryogenesis [4]. In more details, IMP3 is a closed related mRNA binding protein with a molecular mass of $64 \mathrm{KDa}$, which is dominated by gene located on chromosome 7P11.2 $\pm 11 \mathrm{cM}$ whose sequence has been shown to be identical to K-homology domaincontaining protein overexpressed in cancer (KOC) protein sequence [5]. Initially, IMP3 was found to be overexpressed in pancreatic cancer tissue as compared with both normal pancreas and chronic pancreatitis tissue [6]. Since then, aberrant IMP3 expression has been detected in multitude of other human malignancies, including lung cancers, hepatobiliary cancers, gastrointestinal cancers, genitourinary cancers, melanoma and thyroid cancers [7]. What's more, these observations

Correspondence to: Dr. Guo-yue Lv, Department of Hepatobiliary and Pancreatic Surgery, The First Bethune Hospital, Jilin University, Jilin 130021, China, Tel: +86 43188783331; Fax: +86 43188783331; E-mail: lvguoyue@sina.com

Key words: insulin-like growth factor-ii m-rna-binding protein 3 (imp3), prognosis, urological cancer, meta-analysis

Received: March 01, 2015; Accepted: March 13, 2015; Published: March 16, 2015 
suggested that IMP3 can serve as a biomarker for tumor aggressiveness and metastasis and that its expression is associated with a poorer prognosis in many malignancies.

However, the role of IMP3 in urological cancers remains controversial without a firm conclusion, especially in terms of prognosis. Consequently, we performed this systemic review and metaanalysis to investigate whether and how the increased IMP3 expression impacted the prognosis of urological cancers including kidney cancer, urothelial cancer and prostate cancer.

\section{Materials and method}

\section{Search strategy}

A comprehensive literature search of electronic databases PubMed, Cochrane Collaboration, Embase and Wanfang was performed up to January 2015. Search terms included the following: "IMP3" or "Insulin-like growth factor II messenger RNA-binding protein 3"; "kidney" or "renal" or "ureter" or "bladder" or "prostate"; "prognosis" or "survival" or "OS" or "DFS" or "DSS" or "MFS" or "overall survival" or "disease-free survival" or "disease-specific survival" or "metastasisfree survival". References identified in retrieved articles were further screened for potential studies.

\section{Study selection}

The following criteria was used to identify the eligibility of included studies: (1) clinical study that evaluated the correlation between IMP3 expression and prognosis in urological cancers; (2) urological cancer was diagnosed and confirmed by histopathological method; (3) IMP3 expression was detected in primary urological cancer tissue including both formalin-fixed and paraffin-embedded (FFPE) tumor tissues, rather than any other kinds of specimens, eg. serum;

(4) providing information on survival results, such as overall survival (OS), disease-specific survival (DSS), disease-free survival (DFS) and metastasis-free survival (MFS). Articles were considered ineligible if they met any item of the following criteria: (1) articles not about humans; (2) review articles without original data; (3) duplicated articles; (4) articles without key information such as Kaplan-Meier curves, hazard ratio (HR) with its $95 \%$ confidence interval $(\mathrm{CI})$, or any available data that could be used to calculate HR with its $95 \% \mathrm{CI}$. With the help of these inclusion criteria, the title and abstract of all the articles were evaluated on relevance. From the selected articles, the full texts were reviewed, followed by a decision on their eligibility for inclusion.

\section{Data extraction}

Two investigators (DW Sun and YY Zhang) reviewed each included study independently, and controversial problems were resolved by a meeting called by the third investigator (GY Lv). Data tables were made to extract all relevant datas, including the first author, publication year, country, patient number, age, cancer site, cancer stage, detecting methods and positive rate of IMP3 expression. In addition, the study endpoints such as OS, DSS, DFS and MFS, and the follow-up time were also included in the table.

The impact of IMP3 expression on OS, DSS, DFS and MFS was synthesized by hazard ratio (HR). If the HRs and their 95\% CIs were given explicitly in the articles, we used crude ones. When these variables were not directly available, the total numbers of observed deaths/cancer related death/cancer related recurrences/ cancer metastasis and the numbers of samples in each group were extracted to calculateHR[8].

\section{Quality assessment}

Newcastle-Ottawa Scale (NOS) criteria was used to assess the methodological quality of included studies [9]. The NOS criteria is scored based on three aspects: (1) subject selection, (2) comparability of subject, (3) clinical outcome. NOS scores range from 0 to 9 , and a score $\geq 6$ indicates a high quality. Two investigators (Y Qi and YY Zhang) independently assessed the quality of the 8 included studies, and the discrepancies were solved by consensus.

\section{Statistical analysis}

In this meta-analysis, all statistical calculations were performed using STATA 10.0 and SPSS 13.0. HRs with their relative 95\% CIs were used to combine as the effective value to assess the correlation between IMP3 expression and the clinical outcomes in patients with urological cancers. A combined HR $>1$ indicated a worse OS/DSS/ DFS/MFS in patients with IMP-3 expression. Heterogeneity among the studies was determined by chi-square test and $\mathrm{Q}$ test. If heterogeneity was significant $\left(P<0.1\right.$ or $\left.I^{2}>50 \%\right)$, random-effect model was used. Otherwise, fixed-effect model was used. Both Egger's and Begg's tests were used to examine publication bias $[10,11]$. All $P$ values were twosided, and $P<0.05$ was considered as statistically significant.

\section{Results}

\section{Literatures information}

A total of 14 studies potentially relevant citations were retrieved after the initial database searches. 2 studies were excluded from the analysis after the initial screening based on the abstracts or titles, leaving 12 studies available for full-text review. After further reading the fulltext, 4 articles were excluded due to duplicate $(n=2)$, no survival results $(n=1)$, and article in which HR with $95 \%$ CI could not be calculated $(\mathrm{n}=1)$. Eventually, there were 8 English studies included in the present meta-analysis [12-19] (Figure 1).

\section{Characteristics of included studies}

The basic characteristics of the 8 included studies were summarized in Table 2.1 study was conducted in Korea, 1 study was conducted in Switzerland, 2 studies were conducted in Germany, and 3 studies were conducted in America, and the other one was conducted by the Upper

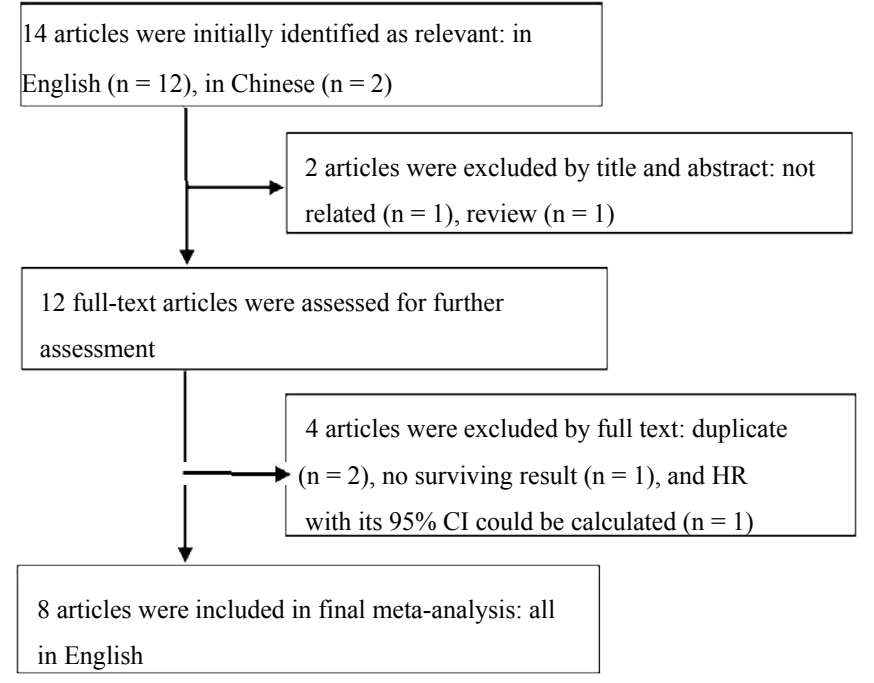

Figure 1. Flowchart of searching relevant studies used in this meta-analysis. 
Table 1. Characteristics of included studies in this meta-analysis.

\begin{tabular}{|c|c|c|c|c|c|c|c|c|c|c|c|c|c|}
\hline 1st author (ref.) & Year & Country & No. & $\begin{array}{l}\text { Mean or } \\
\text { median } \\
\text { age }\end{array}$ & $\begin{array}{l}\text { Cancer } \\
\text { site }\end{array}$ & Cancer stage & $\begin{array}{l}\text { Detecting } \\
\text { methods }\end{array}$ & $\begin{array}{l}\text { Cutoff values for } \\
\text { IMP3 expression }\end{array}$ & $\begin{array}{l}\text { Positive } \\
\text { number } \\
(\%)\end{array}$ & Treatments & $\begin{array}{l}\text { Study endpoints, } \\
\text { HR with } 95 \% \\
\text { CI, Source }\end{array}$ & $\begin{array}{l}\text { Median or } \\
\text { mean } \\
\text { follow-up } \\
\text { (months) }\end{array}$ & Scores \\
\hline Jiang Z [12] & 2006 & America & 371 & NA & Kidney & I-III (AJCC) & IHC & $\begin{array}{l}\text { Staining cells }> \\
30 \%\end{array}$ & $54(14.6)$ & $\begin{array}{l}\text { Radical } \\
\text { resection }\end{array}$ & $\begin{array}{l}\text { OS(M), 4.01 } \\
(2.66-6.05), \text { Direct } \\
\text { MFS(M), 5.84 } \\
(3.60-9.49), \text { Direct }\end{array}$ & $63(1-174)$ & 7 \\
\hline Sitnikova L [13] & 2008 & America & 214 & $68.7 \pm 12.0$ & Bladder & Ta-T1 (AJCC) & IHC & $\begin{array}{l}\text { Dark-brown } \\
\text { cytoplasm } \\
\text { staining }\end{array}$ & $42(19.6)$ & $\begin{array}{l}\text { Multiple } \\
\text { therapies }\end{array}$ & $\begin{array}{l}\text { DFS(M), } 2.82 \\
(1.18-6.71), \text { Direct }\end{array}$ & $35(3-125)$ & 8 \\
\hline Ikenberg K [14] & 2010 & Switzerland & 425 & NA & Prostate & $\mathrm{T} 2-\mathrm{T} 4$ & IHC & $\begin{array}{l}\text { Staining intensity } \\
\geq+\end{array}$ & $354(83.3)$ & $\begin{array}{l}\text { Radical } \\
\text { resection }\end{array}$ & $\begin{array}{l}\text { DFS(U), } 1.18 \\
(0.84-1.65), \text { Data }\end{array}$ & NA (0-167) & 7 \\
\hline Chromecki TF [15] & 2012 & America & 232 & 62.6 & Prostate & Localized & IHC & $\begin{array}{l}\text { Staining cells } \geq \\
10 \%\end{array}$ & $42(18.10)$ & $\begin{array}{l}\text { Radical } \\
\text { resection }\end{array}$ & $\begin{array}{l}\text { DFS(M), } 1.28 \\
(0.63-2.59), \text { Direct }\end{array}$ & $69.0(4.3-113.4)$ & 7 \\
\hline Szarvas T [16] & 2012 & Germany & 106 & NA & Bladder & Ta-T4 & IHC & Score $>8$ & $17(16.0)$ & $\begin{array}{l}\text { Surgical } \\
\text { resection }\end{array}$ & $\begin{array}{l}\text { OS(M), 1.82 } \\
(1.00-3.30), \text { Direct } \\
\text { DSS(M), 2.22 } \\
(1.19-4.14), \text { Direct } \\
\text { MFS(M), 2.42 } \\
(0.96-6.09), \text { Direct }\end{array}$ & 15 (NA-139) & 6 \\
\hline Park JY [17] & 2014 & Korea & 148 & $56.2 \pm 11.6$ & Kidney & T1-T4 (AJCC) & $\mathrm{IHC}$ & $\begin{array}{l}\text { Staining cells } \\
>5 \%\end{array}$ & $43(29.1)$ & $\begin{array}{l}\text { Radical } \\
\text { resection }\end{array}$ & $\begin{array}{l}\text { MFS(M), 3.12 } \\
(1.93-5.05), \text { Data } \\
\text { DSS(M), 1.42 } \\
(1.16-15.04), \text { Direct }\end{array}$ & $55.5(0-227)$ & 8 \\
\hline Szarvas T [18] & 2014 & Germany & 101 & NA & Prostate & Localized & IHC & $\begin{array}{l}\text { Staining cells } \geq \\
10 \%\end{array}$ & $15(15.0)$ & $\begin{array}{l}\text { Radical } \\
\text { resection }\end{array}$ & $\begin{array}{l}\text { OS(M), } 1.09 \\
(0.45-2.62), \text { Direct } \\
\text { DSS(M), 2.06 } \\
(0.73-5.78), \text { Direct }\end{array}$ & 155 (NA-212) & 7 \\
\hline Lee DJ [19] & 2014 & $\begin{array}{l}\text { Several } \\
\text { countries }\end{array}$ & 622 & $69(63-76)$ & UUT & Nonmetastatic & $\mathrm{IHC}$ & $\begin{array}{l}\text { Staining intensity } \\
\geq+\end{array}$ & $76(12.2)$ & $\begin{array}{l}\text { Multiple } \\
\text { therapies }\end{array}$ & $\begin{array}{l}\text { OS(M), } 2.07 \\
(1.45-2.95), \text { Direct } \\
\text { DSS(M), } 2.15 \\
(1.42-3.26), \text { Direct } \\
\text { DFS(M), 1.87 } \\
(1.26-2.78), \text { Direct }\end{array}$ & $27(12-53)$ & 6 \\
\hline
\end{tabular}

Abrreviations: No.: study patient number; NA: not available; UUT: upper urothelial tract (consisting of renal pelvis, ureter and ureter-entero anastomosis); IHC: immunohistochemistry; OS: overall survival; MFS: metastasis-free survival; DSS: disease-specific survival; DFS: disease-free survival; M: multivariate analysis; U: univariate analysis; HR: hazard ratio; CI: confidence interval

Table 2. Subgroup meta-analysis for the association between IMP3 expression and prognosis in patients with urological cancers according to cancer sites.

\begin{tabular}{|c|c|c|c|c|c|c|c|c|}
\hline \multirow{2}{*}{$\begin{array}{l}\text { Categories for } \\
\text { survival results }\end{array}$} & \multirow{2}{*}{$\begin{array}{c}\text { No. of } \\
\text { studies }\end{array}$} & \multirow{2}{*}{$\begin{array}{c}\text { No. of } \\
\text { patients }\end{array}$} & \multirow{2}{*}{$\begin{array}{l}\text { Effect } \\
\text { model }\end{array}$} & \multirow[t]{2}{*}{ HR (95\% CI) } & \multirow[t]{2}{*}{$P$ Value } & \multicolumn{3}{|c|}{ Heterogeneity } \\
\hline & & & & & & $X^{2}$ & $I^{2}(\%)$ & $P$-Value \\
\hline OS & 4 & 1,200 & Random & $2.19(1.35-3.55)$ & $0.001 *$ & 3.18 & 71.6 & 0.014 \\
\hline Kidney cancer + UC & 3 & 1,099 & Random & $2.52(1.55-4.10)$ & $0.000^{*}$ & 3.72 & 72.3 & 0.027 \\
\hline Prostate cancer & 1 & 101 & NA & $1.09(0.45-2.63)$ & 0.848 & 0.19 & NA & NA \\
\hline DSS & 4 & 977 & Fixed & $2.10(1.53-2.89)$ & $0.000^{*}$ & 4.59 & 0.0 & 0.940 \\
\hline Kidney cancer + UC & 3 & 745 & Fixed & $2.11(1.51-2.95)$ & $0.000^{*}$ & 4.38 & 0.0 & 0.819 \\
\hline Prostate cancer & 1 & 232 & NA & $2.06(0.73-5.78)$ & 0.171 & 1.37 & NA & NA \\
\hline DFS & 4 & 1,493 & Fixed & $1.49(1.18-1.87)$ & $0.001 *$ & 3.34 & 43.9 & 0.148 \\
\hline $\mathrm{UC}$ & 2 & 836 & Fixed & $2.01(1.40-2.88)$ & $0.000^{*}$ & 3.79 & 0.0 & 0.399 \\
\hline Prostate cancer & 2 & 657 & Fixed & $1.20(0.88-1.62)$ & 0.245 & 1.16 & 0.0 & 0.839 \\
\hline MFS & 3 & 625 & Random & $3.80(2.27-6.34)$ & $0.000^{*}$ & 5.10 & 55.6 & 0.105 \\
\hline Kidney cancer + UC & 3 & 625 & Random & $3.80(2.27-6.34)$ & $0.000^{*}$ & 5.10 & 55.6 & 0.105 \\
\hline
\end{tabular}

Abrreviations: No.: number; HR: hazard ratio; CI: confidence interval; NA: not available; OS: overall survival; DSS: disease-specific survival; DFS: disease-free survival; MFS: metastasisfree survival; UC: urothelial cancer (consist of renal pelvis cancer, ureter cancer or/and bladder cancer); ${ }^{*}, P<0.05$

Tract urothelial Carcinoma Collaboration from multiple countries including USA, France, Switzerland, Austria, Germany and Italy. In terms of cancer sites, 2 studies were based on kidney cancer, 2 studies were based on bladder cancer, 3 studies were based on prostate cancer, and the other study was based on upper tract urothelial carcinoma (UTUC) consisting of renal pelvis cancer, ureter cancer and ureterentero anastomosis cancer [19]. The included studies were published between 2006 and 2014, and the total number of patients was 2,219 with study sample size ranging from 106 to 622 . All the studies investigated IMP3 expression by the method of immunohistochemistry (IHC). The cutoff values used for determining IMP3 expression were classified into 4 kinds. In more details, "percentage of staining cells" was used in 4 studies, "staining intensity" was used in 2 studies, "dark-brown cytoplasm staining" was used in 1 study, and "score system" was used in the remaining one. In regarding to study endpoints, 4 studies reported in form of OS, 4 studies reported in form of DSS, 4 studies reported 
in form of DFS, and 3 studies reported in form of MFS. Obviously, these four kinds of study endpoints overlapped with each other in some studies. According to the NOS criteria, all of the 8 included studies got a score $\geq 6$, indicating high quality of included studies.

\section{Meta-analysis for the association of IMP3 expression with OS, DSS, DFS and MFS}

Firstly, there were 4 studies with a total of 1,200 patients providing survival result in form of OS. Since the heterogeneity was significant $\left(I^{2}=71.6 \%, P=0.014\right)$, a random-effect model was used to calculate the pooled HR of 2.19 (95\% CI: 1.35-3.55, $P=0.001$ ). The result above showed that IMP3 expression was significantly associated with poor OS, indicating IMP3 expression was an indicator of poor survival rate in patients with urological cancers (Figure 2a). Secondly, there were 4 studies with a total number of 977 patients providing survival result in form of DSS. There was no significant heterogeneity $\left(I^{2}=0.0 \%\right.$, $P=0.940$ ), so a fixed-effect model was used to calculate the pooled HR of 2.49 (95\% CI: 1.73-3.57, $P=0.000$ ). This result showed that IMP3 expression was also significant associated with poor DSS, indicating IMP3 expression was also an indicator of poor disease-specific survival rate in patients with urological cancers (Figure $2 \mathrm{~b}$ ). Thirdly, there were 4 studies with a total number of 1,493 patients providing survival result in form of DFS. There was no significant heterogeneity $\left(I^{2}=43.9 \%, P=0.148\right)$, so a fixed-effect model was used to calculate the pooled HR of 1.49 (95\% CI: $1.18-1.87, P=0.001)$. This result showed that IMP3 expression was significantly associated with poor DFS, indicating IMP3 expression was an indicator of high recurrence rate in patients with urological cancers (Figure 2c). Finally, there were 3 studies with a total number of 625 patients providing survival result in form of MFS. Since the heterogeneity was significant $\left(I^{2}=55.6 \%\right.$, $P=0.105)$, a random-effect model was used to calculate the pooled HR of 3.80 (95\% CI: 2.27-6.34, $P=0.000$ ). This result showed that IMP3 expression was also significantly associated with poor MFS, indicating IMP3 expression was an indicator of tumor metastasis in patients with urological cancers (Figure 2d).

\section{Subgroup meta-analysis for the association of IMP3 expression with OS, DSS, DFS and MFS}

According to the cancer sites (not prostate cancer vs. prostate cancer) we conducted subgroup meta-analysis for the association between IMP3 expression and prognosis in patients with urological cancers (Table 2). Subgroup meta-analysis results showed that IMP3 expression was significantly correlated with poorer prognosis in patients with kidney cancer or urothelial cancer in terms of OS (HR 2.52; 95\% CI 1.55-4.10; $P=0.000$; Random-effect model), DSS (HR 2.11; 95\% CI 1.51-2.95; $P=0.000$; Fixed-effect model), DFS (HR 2.01; $95 \%$ CI 1.40-2.88; $P=0.001$; Fixed-effect model) and MFS (HR 3.80; $95 \%$ CI 2.27-6.34; $P=0.000 ;$ Random-effect model). On the contrary, this significant association was not found in patients with prostate cancer in terms of OS (HR 1.09; 95\% CI 0.45-2.62; $P=0.848$; Model unavailable), DSS (HR 2.06; 95\% CI 0.73-5.80; $P=0.171$; Model unavailable), and DFS (HR 1.20; 95\% CI 0.88-1.62; $P=0.245$; Fixed-effect model).

\section{Publication bias}

In this meta-analysis, both Begg's and Egger's $P$ value tests were used to examine the publication bias. However, no publication bias was observed among studies with OS $(P=0.734,0.450)$, DSS $(P=1.000$, $0.183)$, DFS $(P=0.308,0.492)$ or MFS $(P=1.000,0.652)$. Besides, the Begg's funnel plot shapes showed that included studies did not exhibit apparent asymmetry (Figure $3 \mathrm{a}-\mathrm{d}$ ).
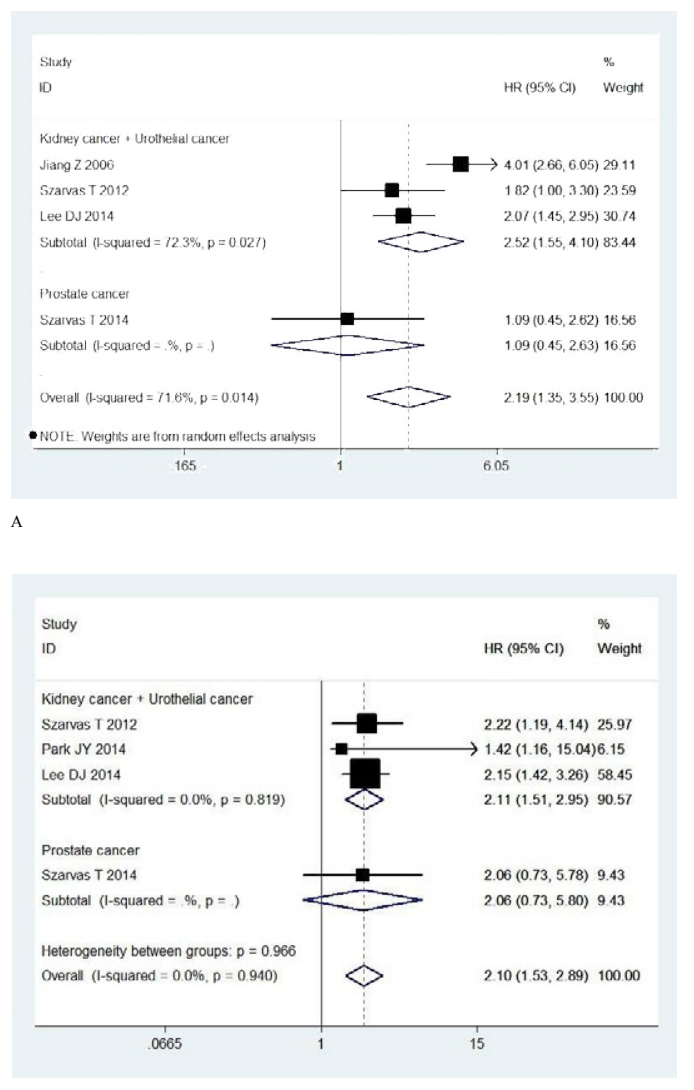

B

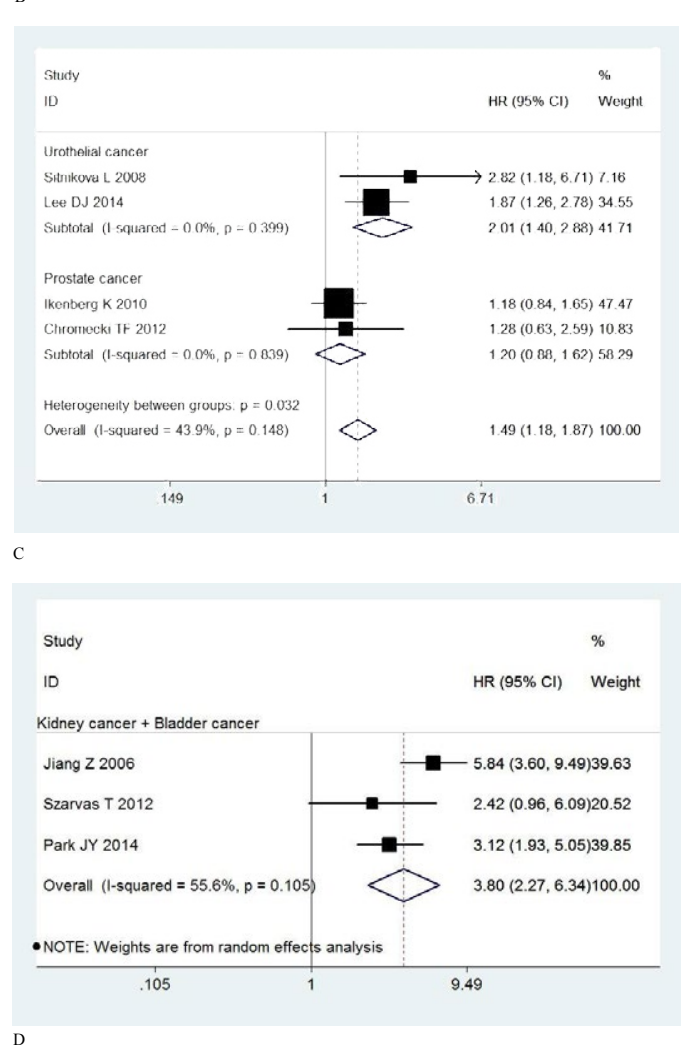

Figure 2. Forest plots of hazard ratio (HR) with $95 \%$ confidence interval (CI) for the association of IMP3 with overall survival (OS) (A), disease-specific survival (DSS) (B), disease-free survival (DFS) (C), and metastasis-free survival (MFS) (D) in patients with urological cancer 

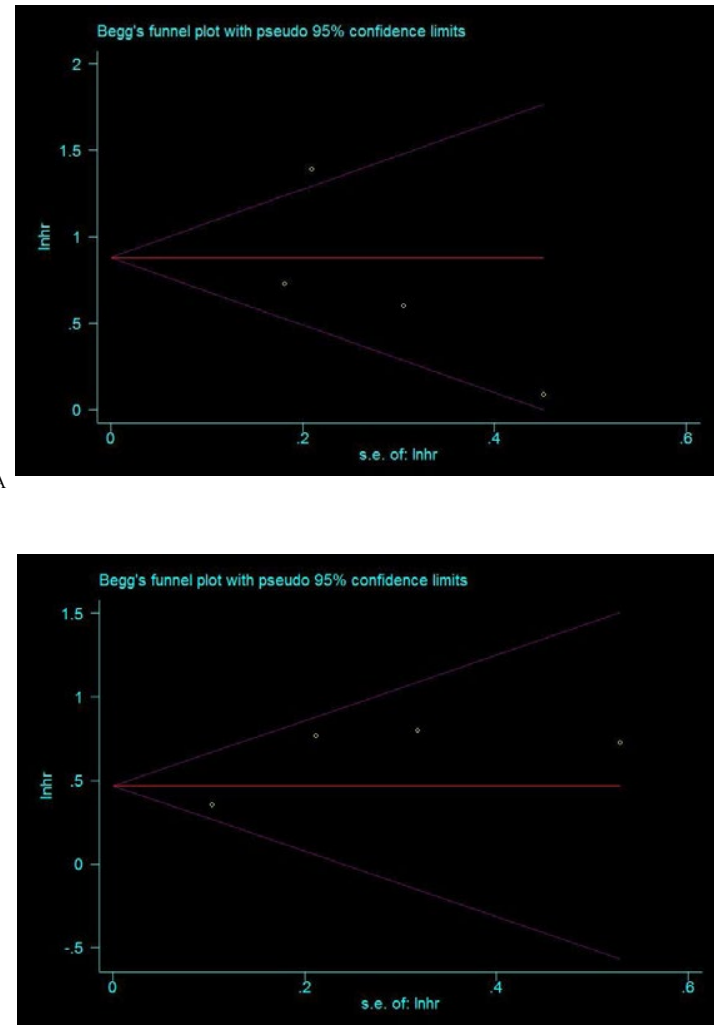

B

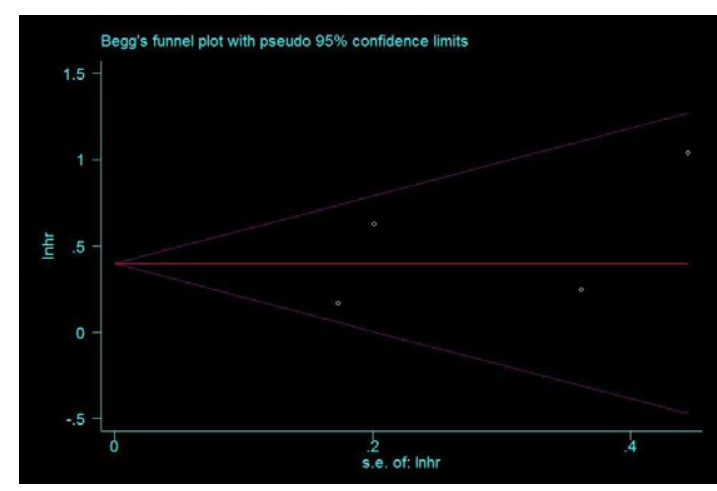

C

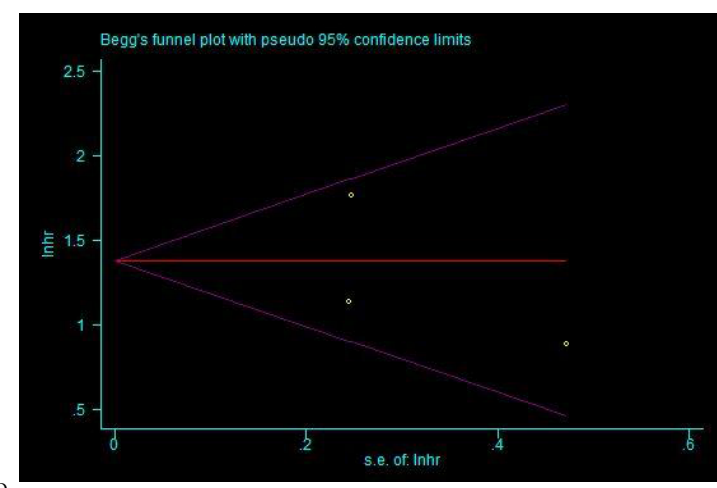

Figure 3. Begg's funnel plots for the association of IMP3 with overall survival (OS) (A), disease-specific survival (DSS) (B), disease-free survival (DFS) (C) and metastasis-free survival (MFS) (D) in patients with urological cancers.

\section{Discussion}

Nowadays, the prognosis of patients with urological cancers has improved with the advances in treatment modalities such as sipulencel-T based immunotherapy and molecular targeted therapy, but there are still a subset of patients deaths within few months after treatments due to the rapid progress of disease [20]. Therefore, it is essential to identify biomarkers that can predict prognosis and metastasis of individual patients with urological cancers.

MP3, a oncofetal protein, is expressed mainly during embryonic development and is epigenetically silenced soon after birth, with little or no detectable protein in normal adult tissues [21]. Recently, IMP3 is reported to be highly expressed in various types of cancer but is not expressed in adjacent benign tissues, and it is associated with tumor aggressiveness as well as poor prognosis $[7,21]$. As far as we know, IMP3 can promote cell proliferation and promote cell survival by inhibiting translation of insulin-like growth factor II (IGF-II) mRNA, eg. studies using human K562 leukemia cells as a model revealed that knockdown of IMP3 markedly inhibited cell proliferation and increased cell apoptosis $[22,23]$. In addition, IMP3 can promote cell adhesion and invasion by regulation of mRNAs encoding extracellular matrix and adhesion proteins during development and cancer formation [24]. What's more, IMP3 can promote the proliferation of human cancer cells by binding the mRNAs of cyclins D1, D3 and G1 (CCND1, D3 and G1), eg. absence of IMP3 dramatically reduced the levels of CCND, D3 and G1 proteins, as a result the cells accumulate in the G1 phase of the cell cycle [25]. Thus, IMP3 abundance correlates with tumor aggressiveness and poor prognosis in malignancies. Here, we first evaluated the correlation of IMP3 expression with the prognosis in patients with urological cancers including kidney cancer, urothelial cancer and prostate cancer by meta-analysis.

In this meta-analysis, we included 8 studies with a total of 2,219 patients with urological cancers including kidney cancer, urothelial cancer and prostate cancer. The pooled results showed that IMP3 expression was a indicator of poor prognosis in terms of OS (HR 2.19; 95\% CI 1.35-3.55; $P=0.001$ ), DSS (HR 2.49; 95\% CI 1.73-3.57; $P=0.000$ ), DFS (HR 1.49; 95\% CI; 1.18-1.87; $P=0.001$ ) and MFS (HR 3.80; $95 \%$ CI 2.27-6.34; $P=0.000)$ in patients with urological cancers. Subgroup analyses showed that IMP3 expression was significantly correlated with poor prognosis in patients with kidney cancer or urothelial cancer in terms of OS (HR 2.52; 95\% CI 1.55-4.10; $P<0.05$ ), DSS (HR 2.11; 95\% CI 1.51-2.95; $P<0.05$ ), DFS (HR 2.01; 95\% CI 1.40-2.88; $P<0.05$ ) and MFS (HR 3.80; 95\% CI 2.27-6.34; $P<0.05$ ), which suggested that IMP3 could serve as an indicator of poor overall survival rate, poor disease-specific survival rate, high recurrence rate and high tumor metastasis rate respectively. However, this association was not found in patients with prostate cancer regarding the forms (OS, HR 2.52, 95\% CI 1.55-4.10, $P>0.05$; DSS, HR 2.06, 95\% CI 0.73-5.80, $P>0.05$; DFS, HR $1.20,95 \%$ CI $0.88-1.62, P>0.05)$. In contrast, a previous study with 94 localized prostate cancer patients identified high IMP3 serum concentration (median as cutoff at $20 \mathrm{ng} / \mathrm{ml}$ ) as an independent riskfactor for cancer specific death in both preoperative (HR 4.99; 95\% CI 1.05-23.72, $P=0.043$ ) and postoperative (HR 3.86; 95\%

CI 1.06-14.04, $P=0.040)$ models [18]. In addition to the prognostic value of IMP3 in urological cancers, many previous studies have shown that IMP3 expression was significantly associated with clinicopathological features such as advanced TNM stage, poor tumor differentiation, and adjacent organ invasion in patients with urological cancers $[12,13,15]$. Therefore, we speculate that IMP3 expression could 
serve as an indicator of prognosis and even may be a potential target for treatment in patients with kidney cancer or urothelial cancer, but further prospective studies are needed to investigate the prognostic role of IMP3 expression in patients with prostate cancer.

However, some limitations of this meta-analysis should be addressed here. The primary concern is that the number of included studies is a little small especially in the subgroup meta-analysis by cancer sites, though the number of patients in most subgroups is more than 600 except two subgroups in which the number of patients are 101 and 232 relatively. Secondly, heterogeneity was found in the main meta-analysis with OS and MFS. Unfortunately, we only conducted subgroup meta-analysis by cancer sites (not prostate cancer vs. prostate cancer) rather than other important clinical factors such as TNM stage or follow-up periods due to insufficient datas. Besides, the cutoff values for determining IMP3 expression were so diverse that this may account for the heterogeneity in some extent. Thirdly, only the studies written in English were included in this meta-analysis though we did not set language limitation in the part of inclusion criteria. Finally, the mechanism that IMP3 promotes tumor progression remains poorly understood until now despite its relatively well-established prognostic value in multiple cancers. Based on these limitations above, the results from our meta-analysis should be interpreted with caution before the application of IMP3 in clinic extensively.

In conclusion, we showed that IMP3 expression was closely correlated with poor OS, poor DSS, poor DFS, and poor MFS in patients with kidney cancer or urothelial cancer. Therefore, IMP3 can serve as an indicator of poor prognosis as well as a potential novel target for treatment in patients with these cancers above. As our study has some limitations, more adequately and well-designed prospective studies especially with better methodology for IMP3 expression assessment are required to clarify the prognostic significance of IMP3 expression in patients with urological cancers especially in prostate cancer.

\section{Acknowledgement}

This study was supported by the Jilin Province Department of Finance.

\section{References}

1. Siegel RL, Miller KD, Jemal A [2015] Cancer statistics. CA Cancer J Clin 65: 5-29.

2. Jemal A, Bray F, Center MM, Ferlay J, Ward E, et al. (2011) Global cancer statistics. CA Cancer J Clin 61: 69-90. [Crossref]

3. Nielsen J, Christiansen J, Lykke-Andersen J, Johnsen AH, Wewer UM, et al. (1999) A family of insulin-like growth factor II mRNA-binding proteins represses translation in late development. Mol Cell Biol 19: 1262-1270. [Crossref]

4. Mueller-Pillasch F, Pohl B, Wilda M, Lacher U, Beil M, et al. (1999) Expression of the highly conserved RNA binding protein KOC in embryogenesis. Mech Dev 88: 95-99. [Crossref]

5. Monk D, Bentley L, Beechey C, Hitchins M, Peters J, et al. (2002) Characterization of the growth regulating gene IMP3, a candidate for Silver-Russell syndrome. $J$ Med Genet 39: 575-581. [Crossref]

6. Müeller-Pillasch F, Lacher U, Wallrapp C, Micha A, Zimmerhackl F, et al. (1997) Cloning of a gene highly overexpressed in cancer coding for a novel KH-domain containing protein. Oncogene 14: 2729-2733. [Crossref]
7. Gong Y, Woda BA, Jiang Z (2014) Oncofetal protein IMP3, a new cancer biomarker. Adv Anat Pathol 21: 191-200. [Crossref]

8. Parmar MK, Torri V, Stewart L (1998) Extracting summary statistics to perform metaanalyses of the published literature for survival endpoints. Stat Med 17: 2815-2834 [Crossref]

9. Stang A (2010) Critical evaluation of the Newcastle-Ottawa scale for the assessment of the quality of nonrandomized studies in meta-analyses. Eur J Epidemiol 25: 603-605. [Crossref]

10. Egger M, Davey Smith G, Schneider M, Minder C (1997) Bias in meta-analysis detected by a simple, graphical test. BMJ 315: 629-634. [Crossref]

11. Begg CB, Mazumdar M (1994) Operating characteristics of a rank correlation test for publication bias. Biometrics 50: 1088-1101. [Crossref]

12. Jiang Z, Chu PG, Woda BA, Rock KL, Liu Q, et al. (2006) Analysis of RNAbinding protein IMP3 to predict metastasis and prognosis of renal-cell carcinoma: a retrospective study. Lancet Oncol 7: 556-564. [Crossref]

13. Sitnikova L, Mendese G, Liu Q, Woda BA, Lu D, et al. (2008) IMP3 predicts aggressive superficial urothelial carcinoma of the bladder. Clin Cancer Res 14: 17011706. [Crossref]

14. Ikenberg K, Fritzsche FR, Zuerrer-Haerdi U, Hofmann I, Hermanns T, et al. (2010) Insulin-like growth factor II mRNA binding protein 3 (IMP3) is overexpressed in prostate cancer and correlates with higher Gleason scores. BMC Cancer.

15. Chromecki TF, Cha EK, Pummer K, Scherr DS, Tewari AK, et al. (2012) Prognostic value of insulin-like growth factor II mRNA binding protein 3 in patients treated with radical prostatectomy. BJU Int 110: 63-68. [Crossref]

16. Szarvas T, vom Dorp F, Niedworok C, Melchior-Becker A, Fischer JW, et al. (2012) High insulin-like growth factor mRNA-binding protein 3 (IMP3) protein expression is associated with poor survival in muscle-invasive bladder cancer. BJU Int 110: E308-E317. [Crossref]

17. Park JY, Choe M, Kang Y, Lee SS (2014) IMP3, a Promising Prognostic Marker in Clear Cell Renal Cell Carcinoma. Korean J Pathol 48: 108-116. [Crossref]

18. Szarvas T, Tschirdewahn S, Niedworok C, Kramer G, Sevcenco S, et al. (2014) Prognostic value of tissue and circulating levels of IMP3 in prostate cancer. Int $J$ Cancer 135: 1596-1604. [Crossref]

19. Lee DJ, Xylinas E, Rieken M, Khani F, Klatte T, et al. (2014) Insulin-like growth factor messenger RNA-binding protein 3 expression helps prognostication in patients with upper tract urothelial carcinoma. Eur Urol 66: 379-385.

20. Wei Y, Jiang YZ, Qian WH (2014) Prognostic Role of NLR in Urinary Cancers: A Meta-Analysis. PLoS One 9: e92079. [Crossref]

21. Yaniv K, Yisraeli JK (2002) The involvement of a conserved family of RNA binding proteins in embryonic development and carcinogenesis. Gene 287: 49-54. [Crossref]

22. Liao B, Hu Y, Herrick DJ, Brewer G (2005) The RNA-binding protein IMP-3 is a translational activator of insulin-like growth factor II leader-3 mRNA during proliferation of human K562 leukemia cells. J Biol Chem 80: 18517-18524. [Crossref]

23. Liao B, Hu Y, Brewer G (2011) RNA-binding protein insulin-like growth factor mRNA-binding protein 3 (IMP-3) promotes cell survival via insulin-like growth factor II signaling after ionizing radiation. $J$ Biol Chem 286: 31145-31152. [Crossref]

24. Vikesaa J, Hansen TV, Jønson L, Borup R, Wewer UM, et al. (2006) RNA-binding IMPs promote cell adhesion and invadopodia formation. EMBO $J$ 25: 1456-1468. [Crossref]

25. Rivera Vargas T, Boudoukha S, Simon A, Souidi M, Cuvellier S, et al. (2014) Posttranscriptional regulation of cyclins D1, D3 and G1 and proliferation of human cancer cells depend on IMP-3 nuclear localization. Oncogene 33: 2866-2875. [Crossref]

Copyright: (C2015 Sun DW. This is an open-access article distributed under the terms of the Creative Commons Attribution License, which permits unrestricted use, distribution, and reproduction in any medium, provided the original author and source are credited. 